\title{
A school-based intervention to reduce overweight and inactivity in children aged 6- 12 years: study design of a randomized controlled trial
}

\author{
Wilma Jansen*1,2, Hein Raat ${ }^{1}$, Evelien Joosten-van Zwanenburg ${ }^{2}$, \\ Ivo Reuvers ${ }^{3}$, Ron van Walsem ${ }^{3}$ and Johannes Brug ${ }^{1,4}$
}

\begin{abstract}
Address: ${ }^{1}$ Department of Public Health, Erasmus MC, Rotterdam, The Netherlands, ${ }^{2}$ Rotterdam Public Health Service and Environs, Rotterdam, The Netherlands, ${ }^{3}$ Municipal Sport and Recreation Department, Rotterdam, The Netherlands and ${ }^{4}$ EMGO Institute, VU University Medical Centre, Amsterdam, The Netherlands

Email: Wilma Jansen* - jansenw@ggd.rotterdam.nl; Hein Raat - h.raat@erasmusmc.nl; Evelien Joosten-van Zwanenburg - ejoosten@ggdzhz.nl; Ivo Reuvers - i.reuvers@senr.rotterdam.nl; Ron van Walsem - r.vanwalsem@senr.rotterdam.nl; Johannes Brug - j.brug@vumc.nl

* Corresponding author
\end{abstract}

Published: 25 July 2008

BMC Public Health 2008, 8:257 doi:10.1 I86/147|-2458-8-257
Received: 9 May 2008

Accepted: 25 July 2008

This article is available from: http://www.biomedcentral.com/I47I-2458/8/257

(C) 2008 Jansen et al; licensee BioMed Central Ltd.

This is an Open Access article distributed under the terms of the Creative Commons Attribution License (http://creativecommons.org/licenses/by/2.0), which permits unrestricted use, distribution, and reproduction in any medium, provided the original work is properly cited.

\begin{abstract}
Background: Effective interventions to prevent overweight and obesity in children are urgently needed especially in inner-city neighbourhoods where prevalence of overweight and inactivity among primary school children is high. A school based intervention was developed aiming at the reduction of overweight and inactivity in these children by addressing both behavioural and environmental determinants.

Methods/design: The main components of the intervention (Lekker Fit!) are the re-establishment of a professional physical education teacher; three (instead of two) PE classes per week; additional sport and play activities outside school hours; fitness testing; classroom education on healthy nutrition, active living and healthy lifestyle choices; and the involvement of parents. The effectiveness of the intervention is evaluated through a cluster randomized controlled trial in 20 primary schools among grades 3 through 8 (6-12 year olds). Primary outcome measures are BMI, waist circumference and fitness. Secondary outcome measures are assessed in a subgroup of grade 6-8 pupils (9-12 year olds) through classroom questionnaires and constitute of nutrition and physical activity behaviours and behavioural determinants. Multilevel regression analyses are used to study differences in outcomes between children in the intervention schools and in control schools, taking clustering of children within schools into account.
\end{abstract}

Discussion: Hypotheses are that the intervention results in a lower prevalence of children being overweight and an improved mean fitness score, in comparison with a control group where the intervention is not implemented. The results of our study will contribute to the discussion on the role of physical education and physical activity in the school curriculum.

Trial registration: [ISRCTN84383524] 


\section{Background}

Effective interventions to prevent overweight and obesity in children are urgently needed.[1] The prevalence of childhood overweight and obesity is increasing worldwide with all its consequences for immediate health, already apparent from increasing health care costs for obesity related morbidity in youth, as well as for health in later life, due to tracking of overweight and obesity into adulthood. [2-9]

The increase in childhood overweight and obesity can be attributed to behavioural and social ecological factors causing long-term imbalance between energy intake and energy expenditure. $[10,11]$ In fact, the environment has been recognized more and more as 'obesogenic' agent in the aetiology of obesity. [12-15] Physical, socio-cultural, economic and political environmental influences on energy balance related behaviours can be distinguished at the micro level (households, schools, neighbourhoods) as well as at the macro level (health care, media, public transport, town planning).[14] Programmes on the prevention of childhood obesity should therefore address both behavioural and environmental determinants.

Many obesity prevention programmes have been developed and evaluated, but so far only yielded 'best practice' recommendations. A recent, large synthesis research of 147 programmes on prevention and treatment of childhood obesity over the last two decades revealed that engagement in physical activity (PA) is a critical intervention in childhood obesity prevention programmes.[1] These findings are supported by other reviews. [16-20]

The school emerged as a critical setting [1]. In a review of 25 school-based childhood overweight prevention programmes 17 of 25 were effective based on a statistically significant reduction in body mass index or skin-folds in the intervention group compared to the control group.[21] Another review included 14 intervention studies in the school arena, of which half were successful and had an effect on either overweight or obesity.[22]

In the Netherlands most recent figures demonstrate that prevalence rates of overweight in 4-16 year olds are rising at an even faster rate than before. Prevalence rates of overweight (including obesity) reached $14.5 \%$ for boys and $17.5 \%$ for girls in 2003 as compared to $9.7 \%$ and $13.0 \%$ in 1997 and 3.9\% and 6.9\% in 1980.[23] The largest increase in prevalence of overweight and obesity in the Netherlands occurred among primary schoolchildren [24] and the highest rates of childhood overweight and obesity are found in ethnic minorities and metropolitan areas [25].
Figures on the amount and trends of PA in Dutch primary school children are largely lacking, but a recent study on physical activity in relation to the physical environment in the Netherlands demonstrated that only $3-5 \%$ of the primary schoolchildren in inner-city neighbourhoods was physically active for the recommended one hour a day, as measured by self-report and accelerometry.[26]

Apparently, relatively high prevalence rates of childhood overweight and obesity coincide with low rates of PA in inner-city neighbourhoods, at least in The Netherlands, urging schools and local governments to take action.

In order to contribute to the prevention of overweight in primary schoolchildren, a school based intervention was developed targeted at the reduction of overweight and inactivity in primary schoolchildren attending schools in inner-city areas in Rotterdam addressing both behavioural and environmental determinants. This paper describes the intervention and the study design for assessing the effectiveness of the intervention.

\section{Methods/design \\ The intervention}

The intervention Lekker Fit!, which can be translated as 'enjoy being fit', focuses on the promotion of healthy eating behaviour and active living rather than the achievement of an ideal body weight. By choosing this focus the intervention aims to reduce the chance of stigmatization of overweight children and of contributing to eating disorders or distorted perceptions of body image. $[1,27,28]$

The intervention targets individual behaviours as well as the environment and is based on the theory of planned behaviour $[29,30]$ and the ecological model of Egger and Swinburn.[31] According to the theory of planned behaviour a given behaviour can be predicted form the intention to display that behaviour. The intention in turn is predicted by attitude, social influence and self-efficacy. The model acknowledges perceived behavioural control as a potential barrier between intention and behaviour. Within the ecological model the intervention concentrates on the physical and socio-cultural environmental influences on energy balance related behaviours, especially PA, within the micro environment of schools and to a lesser extent of home environments.

The targeted population consists of children attending primary schools in the more deprived, inner-city areas of Rotterdam where prevalence rates of overweight and obesity are relatively high.[32]

The intervention consists of multiple components, which will be described below. 


\section{Intervention components}

Three physical education (PE) classes a week by a professional PE teacher

The first component of the intervention constitutes a structural change in the school environment by the implementation of three PE sessions a week during school hours by a professional PE teacher for grades 3 through 8 (6-12 years of age). The usual curriculum of primary schools consists of two PE sessions a week by the classroom teacher or a professional PE teacher, dependent on the schools policy. The PE teachers of the intervention are paid for and supervised by the Municipal Sport Department for two years and arrange their lessons according to a standardised protocol.[33]. Participating schools express the intention to keep the PE teacher after the two year intervention period.

\section{Sport and play activities outside school hours}

A second component of the intervention is the organisation of additional sport and play activities outside school hours. These non-curricular activities are organised by the PE teacher and can be attended by the children on a voluntary basis. The focus of the activities is enjoying physical activity. Fun activities like rope skipping and dance are examples of the organized activities.

The total number of days a week children can be involved in sport and play activities inside and outside school hours ranges between 3 (only within school hours) to 5 (within and outside school hours).

\section{Cooperation with Sport clubs}

A third component of the intervention is the cooperation with local sport clubs and professional sport clubs. Local sports clubs are given the opportunity to present themselves during PE classes and outside school hours in order to let pupils get acquainted with several types of sports and promote sport club membership. Moreover, sport clubs are encouraged and supported by the Municipal Sport Department to establish satellite clubs in the more deprived neighbourhoods.

\section{Eurofit test and Fitmeter}

At the beginning and at the end of the school year the Eurofit test is administered by trained staff from the Municipal Sport Department during PE class.

The Eurofit test comprises of measurements of height, weight and nine different fitness tests, i.e. measuring balance, endurance, flexibility, power, speed and strength as shown in table 1.[34] The skin fold measurements that originally are part of the Eurofit test battery are replaced by the simpler and quicker measurement of waist circumference.

Children receive a score card (see figure 1) to take home with their test results compared with reference scores [35]. When their BMI is above age and gender specific thresholds for overweight [36] parents receive a letter and are offered individual counselling by the school nurse. When needed motoric remedial teaching is offered.

All individual Eurofit scores are stored in a web-based computer application - the Fitmeter - that was especially developed for this purpose and allows PE teachers to follow the development and progress of individual pupils and classes in comparison with reference scores. Additionally, the Fitmeter offers PE teachers a planning module for within and after school hour's activities and a registration module for attendance to voluntary activities of individual pupils.

Table I: Description of the Eurofit test components, dimensions tested and units of measurement.

\begin{tabular}{|c|c|c|c|}
\hline Test component & Dimension & Description & Unit of measurement \\
\hline Flamingo balance & Balance & $\begin{array}{l}\text { Standing for I minute on one leg, while holding the other leg } \\
\text { bend backwards in one hand }\end{array}$ & Number of attempts that were needed \\
\hline Plate tapping & Speed & $\begin{array}{l}\text { Tapping } 2 \text { plates (edges } 60 \mathrm{~cm} \text { apart) alternately, with the } \\
\text { preferred hand, until each plate was touched } 25 \text { times. }\end{array}$ & $\begin{array}{l}\text { Time needed measured to the nearest } 0.1 \\
\text { second. }\end{array}$ \\
\hline Sit and reach & Flexibility & $\begin{array}{l}\text { Bending the trunk and reaching forward as far as possible while } \\
\text { sitting on the floor with stretched legs and with the feet placed } \\
\text { against a test box with a ruler placed on the top of the box. }\end{array}$ & $\begin{array}{l}\text { Difference between feet soles and the tip of } \\
\text { the largest finger measured in } \mathrm{cm} \text {. }\end{array}$ \\
\hline Standing broad jump & Power & Jumping from standing position & Distance in $\mathrm{cm}$ \\
\hline Hand-grip & Strength & $\begin{array}{l}\text { Squeezing a hand-dynamo meter as hard as possible with } \\
\text { preferred hand }\end{array}$ & $\mathrm{Kg}$ to nearest $0.5 \mathrm{~kg}$ \\
\hline Sit-ups & Endurance & Making as many sit ups as possible for $30 \mathrm{sec}$ & Number of sit ups \\
\hline Bent-arm hang & Endurance & $\begin{array}{l}\text { Maintaining a bent arm position with an over-grip as long as } \\
\text { possible while hanging from a bar. }\end{array}$ & Duration measured to the nearest $0.1 \mathrm{sec}$. \\
\hline $10 \times 5 \mathrm{~m}$ shuttle run & Speed agility & Running as fast as possible 10 times between 2 lines, $5 \mathrm{~m}$ apart. & Time in sec. \\
\hline 20 m shuttle run & Endurance & $\begin{array}{l}\text { Running } 20 \mathrm{~m} \text { forth and back with an initial running pace of } 8.0 \\
\mathrm{~km} / \mathrm{h} \text { and a progressive } 0.5 \mathrm{~km} / \mathrm{min} \text { raise of the running speed } \\
\text { given by a sound. }\end{array}$ & Last completed stage with a precision of 0.5 . \\
\hline
\end{tabular}




\section{Jouw gegevens}

School

Voornaam

Achternaam

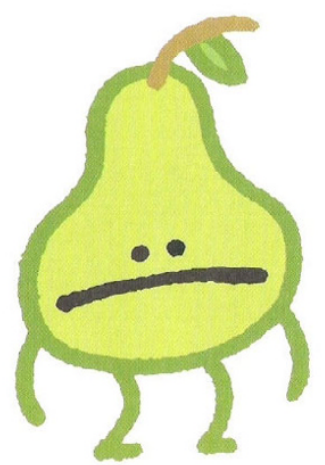

kan beter

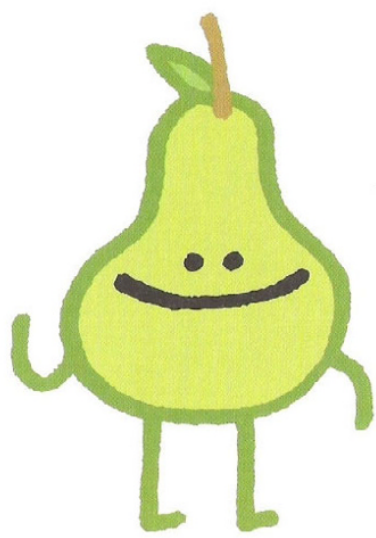

goed
Groep

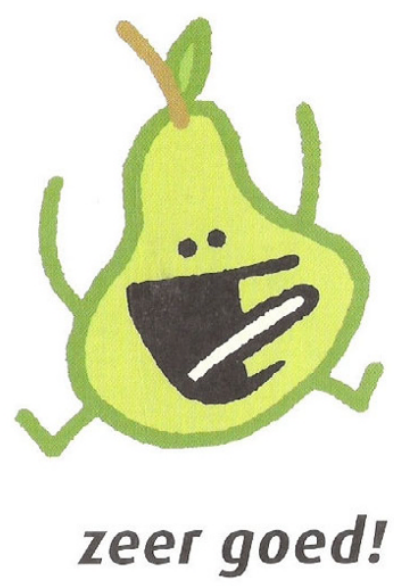

\section{Scorekaart Eurofittest}

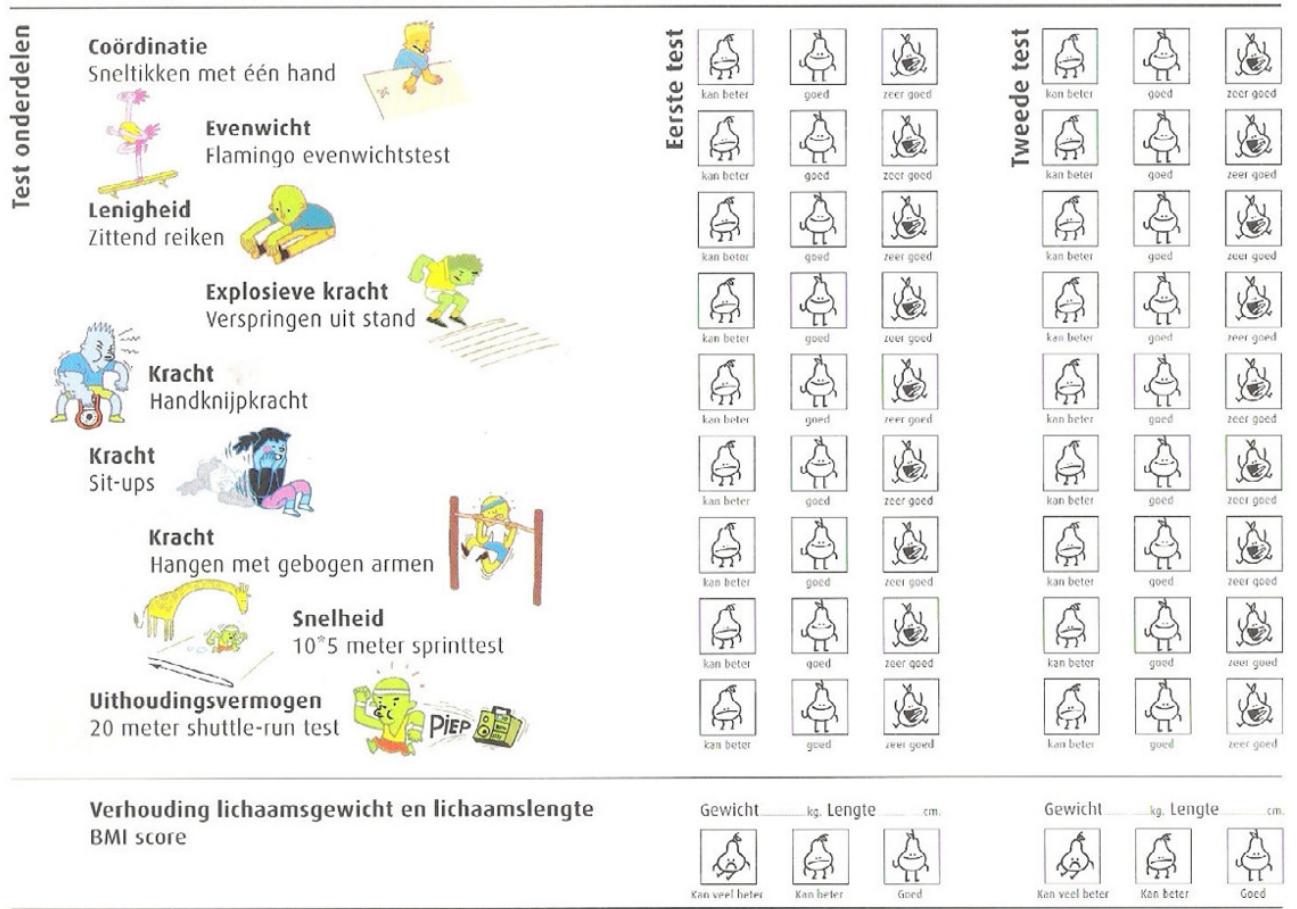

Figure I

Score card with individual fitness scores, height, weight and weight status. 
Parents provide informed consent for storing test results in the Fitmeter and sharing individual scores with the Municipal Sport and Recreation department and Municipal Health Department for evaluation purposes.

\section{Classroom education}

Three classroom lessons and an introduction lesson are developed for all grades. The three lessons deal with healthy nutrition, active living and healthy lifestyle choices and are provided by the regular classroom teacher, who receives an extensive manual on the lessons. Central theme of the lessons is to enjoy a fit and healthy lifestyle. Each lesson starts with a homework assignment to be completed with the help of the parents. Assessment and awareness of the child's behaviour are the central themes of the home assignment. Each classroom lesson consists of a theoretical and practical part, during which knowledge is transferred and subsequently applied through activities like games, puzzles and tests. Each lesson finishes with goal setting by drawing up a joint agreement regarding lifestyle for the period until the next lesson. Education material and classroom posters for writing down the agreements are part of the provided material http://www.lekkerfitopschool.nl.

\section{Parent involvement}

Parents are important agents in shaping children's eating and physical activity behaviours. [27,37-40] Besides the homework assignments and fitness score card, parents are involved by providing them with written information on the intervention and inviting them for a gathering at the beginning of the school year. During this gathering information is provided by the school nurse or a dietician about a healthy lifestyle, focusing on reducing sedentary activities (watching TV and playing on the computer), promotion of outdoor play, and reduction of sugar-sweetened beverage intake and promotion of having breakfast daily. All of these behaviours have been shown to be associated with childhood obesity.[41,42]

\section{The study on the effectiveness \\ Study design and procedures}

A cluster randomized controlled study design is used to evaluate the effectiveness of the intervention with baseline measurements at the beginning of the school year 2006/ 2007 and follow-up measurements at the end of the same school year.

The main outcome measures consist of BMI, waist circumference and fitness and are measured among all pupils of grade 3 through 8 by trained staff during physical education class. High levels of habitual PA and increases in PA have been shown to be associated with improvements of fitness in children [43-46].
Secondary outcome measures consist of selected energy balance related behaviours and possible mediators and moderators as described in the Environmental Research Framework for weight Gain prevention. [12] In this framework energy balance related behaviours are influenced by environmental influences in a direct way or an indirect way through cognitive mediators (attitude, subjective norm, perceived behavioural control and intention).

Moderators of the relations between environmental influences and cognitive mediators on the one hand and energy balance related behaviours (i.e. specific nutrition and physical activity behaviours that contribute significantly to energy balance) on the other hand, are personality, awareness, habit strength, clustering of behaviours and personal characteristics like gender, ethnicity, and socio-economic status. Secondary outcome measures are gathered via classroom questionnaires in a subgroup of the study population consisting of grades 6 through 8 (9-12 years of age), administered on a normal weekday except for Mondays and guided by the classroom teacher. The questionnaire was developed in the ENDORSE-study and adjusted to make it better applicable to primary schoolchildren.[47]

Parents receive written information on the study and provide their informed consent. Children in grades 6 through 8 also receive written information on the study. The study is approved by the Medical Ethics Committee of Erasmus MC.

\section{Recruitment and randomization procedure}

Primary schools in Rotterdam with large populations of foreign ethnicity were free to apply for participation in the intervention, which was already implemented on 30 schools in the school year 2005/2006. Spontaneous applications made further active recruitment unnecessary. Schools that applied for participation were informed of the study and were offered a chance of $50 \%$ to participate in school year $2006 / 2007$ versus a chance of $50 \%$ to be allocated to the control group in school year 2006/2007 continuing with their usual curriculum and to participate in the intervention in the next school year 2007/2008. All of the 27 schools that spontaneously applied, agreed to participate in the study. Schools were paired according to size, ethnicity and neighbourhood into 13 comparable pairs. One school could not be paired and was excluded from the study. Randomization took place within each pair with the toss of a coin.

After randomization 3 pairs were lost to the study, due to withdrawal of schools (1 pair) and implementation of the intervention components prior to the study (2 pairs). 
Eventually, twenty primary schools located in multi-ethnic, mostly low-income, inner-city neighbourhoods in Rotterdam participated in the study.

\section{Measures}

Anthropometric measures

Body mass index (BMI) was calculated using weight (kg) divided by squared height (in $\mathrm{m}$ ). Height was measured to the nearest $0.1 \mathrm{~cm}$ using a commercial mobile stadiometer, and weight was measured to the nearest $0.2 \mathrm{~kg}$ using a flat electronic weighing scale (SECA 888) in light (sport) clothing following a standardized protocol [48]. Pupils were categorised as underweight, normal weight, overweight, or obese. Overweight and obesity were defined using the age and gender specific cut-offs that correspond to adult cut-offs for BMI of 25 and $30 \mathrm{~kg} / \mathrm{m}^{2}$ as published by the International Obesity Task Force (IOTF) [36]. Underweight was defined using the age and gender specific cut-offs corresponding to adult cut-offs for BMI of $18.5 \mathrm{~kg} / \mathrm{m}^{2}$ derived from the $1996 / 1997$ Dutch national growth survey [49].

Waist circumference was measured over the naked skin using flexible bands (SECA) with an accuracy of $0.1 \mathrm{~cm}$, half-way between the lower rib and the top of the iliac crest at the end of a gentle expiration. [50]

\section{Fitness}

Fitness was assessed by the Eurofit test. [34,35] See figure 1 . The first 8 test components were administered during one PE session, the shuttle run test was administered one week later.

\section{Questionnaires}

\section{Energy balance related behaviours}

Physical activity was measured using the following questions: i) 'How long did you play outdoors after school yesterday?' ('did not'/'less than half an hour'/'1/2-1 hour'/ '1-2 hours', '2-3 hours', 'more than 3 hours'); ii) 'On how many days did you do sport outside school hours last week?' (0 through 7); iii) 'How did you come to school today?' ('walking'/'cycling'/'public transport or car'/ 'other'); iv) on how many days last week did you walk or cycle to school? (0 through 5). Dutch norms on minimal requirements for physical activity for children state that children should be active at least 1 hour a day and engage in sports twice a week.[51]

Sedentary behaviour was assessed using two questions: i) 'How long did you watch television, DVD or video outside school hours yesterday?' ('did not'/'less than half an hour'/'1/2-1 hour'/'1-2 hours', '2-3 hours', 'more than 3 hours')'; ii) 'How long did you spend on the computer or game-computer outside school hours yesterday?' ('did not'/'less than half an hour'/'1/2-1 hour'/'1-2 hours', '2-3 hours', 'more than 3 hours'). A maximum of 2 hours screen time per day is the recommendation given by youth health care in the Netherlands [52].

Consumption of sugar-containing drinks was assessed with two questions, after giving examples of such drinks (i.e. lemonade, soft drinks, sport drinks, chocolate milk, yoghurt drinks, fruit juices; exceptions: light drinks, orange or grapefruit juice): i) 'How many glasses of sugarcontaining drinks did you have yesterday?' (0 through 5 or more); ii) 'How many days last week did you take sugar-containing drinks to school?'(0 through 5). A maximum of 2 sugar-containing drinks a day is recommended by Dutch Youth Health care.[52]

Consumption of fruit (including orange juice and grapefruit juice), was assessed with two questions, after giving examples of pieces of fruit: i) 'How many pieces of fruit did you have yesterday?' $(0,1 / 2,1,11 / 2,2$ or more); ii) 'How many glasses of orange or grapefruit juice did you have yesterday?' $(0,1,2$ or more). Two pieces of fruit a day or one piece of fruit in combination with one glass of orange or grapefruit juice is the Dutch recommendation for children (9-12 years).[53]

Skipping breakfast was measured with two questions: i) Did you have breakfast this morning?' ('yes'/'no'); ii) 'on how many days last week did you have breakfast before going to school?'

\section{Potential mediators and moderators}

As potential mediators attitudes and intentions towards energy balance related behaviours were included in the questionnaire. Attitudes towards outdoor playing, doing sports, watching television, using computer, having sugarcontaining drinks, having fruits and having breakfast were measured with two questions: i.e. "I think (selected energy balance behaviour) is ...." ('very good'/'good'/'not good, not bad'/'bad'/'very bad') and "I think (selected energy balance behaviour) is ...." ('very nice'/'nice'/'not that nice'/ 'not nice at all'), representing cognitive and affective attitudes. Intentions to engage in outdoor playing, doing sports, having fruits, having breakfast, and to reduce television time, computer time and consumption of sugarcontaining drinks were measured with single-item questions: i.e. "Do you intend to increase your outdoor play, to (continue) doing sports, to reduce TV time, to reduce computer time, to reduce consumption of sugar-containing drinks, to increase consumption of fruits, to (continue) having breakfast in the coming 6 months?"('yes certainly'/'yes probably'/'maybe yes, maybe no'/'probably not'/'certainly not'.

As potential moderators perceived health ('very good'/ 'good'/'moderate'/'not well'/'bad'), body weight percep- 
tion ('far too thin'/'little too thin'/'not thin, not fat'/'little too fat'/'far too fat'), weight worries ('no'/'a little'/'a lot'), being member of a sports club ('yes'/'no'), owning a bicycle, having a television in one's bedroom, having a computer and/or game-computer at home and questions on sport participation of father and mother ('never'/'seldom'/'once a week'/'more than once a week') and body size of father and mother using Stunkard's body figure rating scales [54] were included as single item questions in the questionnaire.

\section{Socio-demographic characteristics}

Socio-demographic characteristics included gender, age, ethnicity and postal code.

Ethnicity is determined by country of birth of mother and father according to definitions of Statistics Netherlands. If both parents have been born in the Netherlands, the child's ethnicity is defined as Dutch; if one or both parents are born in another country, ethnicity is defined according to that country; if both parents have been born in different foreign countries, the country of birth of the mother is deemed most important.

Postal code is used to determine neighbourhood income level. Most recent data on average 2003 personal gross income level per postal code are provided by Statistics Netherlands. Postal codes refer to on average 20 (SD 17) houses and 46 (SD 38) inhabitants.

\section{Process measures}

Process measures are taken from the Fitmeter, registration forms for classroom teachers and registration forms for the school nurse or dietician.

\section{Power considerations and data analysis}

Power calculations showed a total number of children of 2,778 children in 20 schools are needed to detect a difference of $0.45 \mathrm{~kg} / \mathrm{m}^{2}$ between intervention and control group, assuming a standard deviation of $3.0 \mathrm{~kg} / \mathrm{m}^{2}$ for BMI and an intraclass correlation of 0.01 [55], with a power of 0.80 en alpha 0.05 (one-sided) and accounting for $10 \%$ loss to follow up.

Multilevel regression analysis will be used to test for posttest group differences on the main outcome measures corrected for pre-test measurements. [56]

\section{Discussion}

The intervention combines structural changes in the amount of PA children receive with behavioural change through the school curriculum. A specific element is the implementation of three PE classes a week by a professional PE teacher, while two PE classes a week by a classroom teacher constitute the usual mandatory curriculum.
Another specific characteristic of the intervention is the targeting of a population with relatively low SES and a high proportion of migrant children. A population that has been underserved so far. [1]

Several evaluated obesity prevention programmes have targeted PE or increased PA in the primary school setting. [57-68] Most of these interventions altered the content of existing PE lessons [59-61,63-65,68], others increased PA in the classroom [62] or during breaks [66]. Only a few actually augmented the amount of PE lessons a week for six months [57] or for 8 weeks[67].

Strengths of the study are the use of a cluster randomized controlled study design, the size of the study and the objectively measured primary outcome measures of weight status and fitness.

Weaknesses of the study are that secondary outcome measures are derived from self-report questionnaires and no objective measure of PA is used. Furthermore, in the self-report questionnaires the choice was made to measure a large amount of concepts to cover all aspects of the intervention. To keep the length of the questionnaires acceptable for children in the age of 9-12 years many single item questions were used at the cost of using validated questionnaires. The debate on self-report by children largely concerns recall problems of actual energy balance related behaviours. [69] We took those into account by making recall periods short. Self-reports by children on determinants of energy balance related behaviours like attitudes and intentions have not been subject to debate.

We hypothesize that the intervention will reduce the number of overweight children and improve fitness scores due to increased physical activity in comparison with the control condition. Furthermore, we hypothesize that the intervention will impact positively on energy balance related behaviours and its determinants in the intervention group as compared to the controls.

The results of our study are especially important for decisions on the amount of PE classes in the usual school curriculum and the position of a professional PE teacher within this curriculum.

\section{Competing interests}

The authors declare that they have no competing interests.

\section{Authors' contributions}

WJ designed the study and drafted the manuscript. EJvZ participated in the design of the study. IR and RvW participated in the design of the intervention and provided feedback on the drafts. JB and HR provided critical feed- 
back on the study and drafts. All authors approved the final manuscript.

\section{References}

I. Flynn MA, McNeil DA, Maloff B, Mutasingwa D, Wu M, Ford C, Tough SC: Reducing obesity and related chronic disease risk in children and youth: a synthesis of evidence with 'best practice' recommendations. Obes Rev 2006, 7 Suppl I:7-66.

2. Deckelbaum RJ, Williams CL: Childhood Obesity: The Health Issue. Obes Res 200I, 9:S239-243.

3. Dietz WH: Health consequences of obesity in youth: childhood predictors of adult disease. Pediatrics 1998, I 0 I:5 I 8-525.

4. Ebbeling CB, Pawlak DB, Ludwig DS: Childhood obesity: publichealth crisis, common sense cure. The Lancet 2002 , 360:473-482.

5. Must A, Strauss RS: Risks and consequences of childhood and adolescent obesity. Int J Obes Relat Metab Disord I999, 23 Suppl 2:S2-II.

6. Saland JM: Update on the metabolic syndrome in children. Curr Opin Pediatr 2007, 19:183-191.

7. Wabitsch M: Overweight and obesity in European children definition and diagnostic procedures, risk factors and consequences for later health outcome. Eur J Pediatr 2000, I 59 Supp I:S8-13.

8. Lobstein T, Baur LA: Policies to prevent childhood obesity in the European Union. Eur J Public Health 2005, I 5:576-579.

9. Wang G, Dietz WH: Economic Burden of Obesity in Youths Aged 6 to 17 Years: 1979-1999. Pediatrics 2002, I09:e8I.

10. Baranowski T, Cullen KW, Nicklas T, Thompson D, Baranowski Are current health behavioral change models helpful in guiding prevention of weight gain efforts? Obes Res 2003, I Suppl:23S-43S.

I I. Brug J, van Lenthe FJ, Kremers SPJ: Revisiting Kurt Lewin: How to Gain Insight into Environmental Correlates of Obesogenic Behaviors. American Journal of Preventive Medicine 2006, 3 I:525-529.

12. Kremers S, de Bruijn G], Visscher T, van Mechelen W, de Vries N Brug J: Environmental influences on energy balance-related behaviors: A dual-process view. International Journal of Behavioral Nutrition and Physical Activity 2006, 3:9.

13. Cohen DA, Scribner RA, Farley TA: A Structural Model of Health Behavior: A Pragmatic Approach to Explain and Influence Health Behaviors at the Population Level. Preventive Medicine 2000, 30:| $46-154$

14. Swinburn B, Egger G, Raza F: Dissecting Obesogenic Environments: The Development and Application of a Framework for Identifying and Prioritizing Environmental Interventions for Obesity. Preventive Medicine 1999, 29:563-570.

15. Lobstein T, Baur L, Uauy R: Obesity in children and young people: a crisis in public health. Obes Rev 2004, 5 Suppl I:4- I04.

16. Goran MI, Reynolds KD, Lindquist $\mathrm{CH}$ : Role of physical activity in the prevention of obesity in children. Int J Obes Relat Metab Disord 1999, 23 Suppl 3:S18-33.

17. Steinbeck KS: The importance of physical activity in the prevention of overweight and obesity in childhood: a review and an opinion. Obesity Reviews 2001, 2:1 I7-130.

18. Campbell K, Waters E, O'Meara S, Kelly S, Summerbell C: Interventions for preventing obesity in children. Cochrane Database Syst Rev 2002:CD00187I.

19. Summerbell C, Waters E, Edmunds L, Kelly S, Brown T, Campbell K: Interventions for preventing obesity in children. Cochrane Database Syst Rev 2005:CD00187I.

20. van Sluijs EM, McMinn AM, Griffin SJ: Effectiveness of interventions to promote physical activity in children and adolescents: systematic review of controlled trials. Bmj 2007, 335:703

21. Doak CM, Visscher TLS, Renders CM, Seidell JC: The prevention of overweight and obesity in children and adolescents: a review of interventions and programmes. Obesity Reviews 2006, 7:111-136.

22. Lissau I: Prevention of overweight in the school arena. Acto Paediatr Suppl 2007, 96:12-18.

23. van den Hurk $K$, van Dommelen $P$, van Buuren $S$, Verkerk $P H$, HiraS ing RA: Prevalence of overweight and obesity in the Netherlands in 2003, compared to 1980 and 1997. Arch Dis Child 2007 92:992-995
24. Hirasing RA, Fredriks AM, van Buuren S, Verloove-Vanhorick SP, Wit JM: [Increased prevalence of overweight and obesity in Dutch children, and the detection of overweight and obesity using international criteria and new reference diagrams] Toegenomen prevalentie van overgewicht en obesitas bij Nederlandse kinderen en signalering daarvan aan de hand van internationale normen en nieuwe referentiediagrammen. Ned Tijdschr Geneeskd 200 I, I 45: I 303-I308.

25. Fredriks AM, Van Buuren S, Sing RA, Wit JM, Verloove-Vanhorick SP Alarming prevalences of overweight and obesity for children of Turkish, Moroccan and Dutch origin in The Netherlands according to international standards. Acta Paediatr 2005 94:496-498.

26. De Vries SI, Bakker I, Van Overbeek K, Boer ND, Hopman-Rock M: Children in priority neighbourhoods: physical (in)activity and overweight [Kinderen in prioriteitswijken: lichamelijke (in)activiteit en overgewicht]. Leiden, TNO Kwaliteit van Leven; 2005

27. Golan M, Crow S: Parents are key players in the prevention and treatment of weight-related problems. Nutr Rev 2004, 62:39-50.

28. Swinburn B, Egger G: Preventive strategies against weight gain and obesity. Obes Rev 2002, 3:289-30I.

29. Ajzen I, Madden TJ: Prediction of Goal-Directed Behavior: Attitudes, Intentions, and Perceived Behavioral control. J Exp Soc Psy 1986, 22:453-474

30. Godin G, Kok G: The theory of planned behavior: a review of its applications to health-related behaviors. Am J Health Promot | 996, I | :87-98.

31. Egger G, Swinburn B: An "ecological" approach to the obesity pandemic. Bmj 1997, 3 I 5:477-480.

32. Jansen W, Hazebroek-Kampschreur AA: Differences in height and weight between children living in neighbourhoods of different socioeconomic status. Acta Paediatr 1997, 86:224-225.

33. Mooij C, Van berkel M, Hazelebach C: Basisdocument Bewegingsonderwijs. Edited by: KVLO SLO. Zeist, Jan Luitingfonds; 2004

34. Adam $C$, Klissouras $V$, Ravazzolo $M$, Reson $R$, Tuxworth $W$ EUROFIT : Eurofit Test of Physical Fitness. Rome, Council of Europe, Committee for the Development of Sport; 1988.

35. Lefevre J, Beunen G, Borms J, Vrijens J, Claessens AL, Van der Aerschot $\mathrm{H}$ : Eurofit testbatterij. Leidraad bij de testafneming. , Publicatiefonds voor Lichamelijke Opvoeding; 1993.

36. Cole TJ, Bellizzi MC, Flegal KM, Dietz WH: Establishing a standard definition for child overweight and obesity worldwide: international survey. Bmj 2000, 320:1240-1243.

37. Trost SG, Sallis JF, Pate RR, Freedson PS, Taylor WC, Dowda M: Evaluating a model of parental influence on youth physical activity. American Journal of Preventive Medicine 2003, 25:277-282.

38. Golan M: Parents as agents of change in childhood obesity-from research to practice. Int J Pediatr Obes 2006, I:66-76.

39. Ritchie LD, Welk G, Styne D, Gerstein DE, Crawford PB: Family Environment and Pediatric Overweight: What Is a Parent to Do? Journal of the American Dietetic Association 2005, I 05:70-79.

40. Bauer KW, Nelson MC, Boutelle KN, Neumark-Sztainer D: Parental influences on adolescents' physical activity and sedentary behavior: longitudinal findings from Project EAT-II. Int Behav Nutr Phys Act 2008, 5:12.

41. Whitaker RC: Obesity prevention in pediatric primary care: four behaviors to target. Arch Pediatr Adolesc Med 2003, I 57:725-727.

42. Barlow SE, and the Expert Committee: Expert Committee Recommendations Regarding the Prevention, Assessment, and Treatment of Child and Adolescent Overweight and Obesity: Summary Report. Pediatrics 2007, I 20:S164-192.

43. Buchheit M, Platat C, Oujaa M, Simon C: Habitual Physical Activity, Physical Fitness and Heart Rate Variability in Preadolescents. International Journal of Sports Medicine 2007:204-2I 0.

44. Annesi JJ, Westcott WL, Faigenbaum AD, Unruh JL: Effects of a I 2 week physical activity protocol delivered by YMCA afterschool counselors (Youth Fit for Life) on fitness and self-efficacy changes in 5-12-year-old boys and girls. Res $Q$ Exerc Sport 2005, 76:468-476.

45. Barbeau $P$, Johnson $M H$, Howe CA, Allison J, Davis CL, Gutin B, Lemmon CR: Ten Months of Exercise Improves General and Visceral Adiposity, Bone, and Fitness in Black Girls. Obesity 2007, 15:2077-2085. 
46. Baquet G, Guinhouya C, Dupont G, Nourry C, Berthoin S: Effects of a short-term interval training program on physical fitness in prepubertal children. J Strength Cond Res 2004, I 8:708-7।3.

47. van der Horst K, Oenema A, van de Looij-Jansen P, Brug J: The ENDORSE study: research into environmental determinants of obesity related behaviors in Rotterdam schoolchildren. BMC Public Health 2008, 8: 142

48. Bulk-Bunschoten AMW, Renders CM, Leerdam FJM, Hirasing RA: Protocol for detection of overweight in preventive youth health care. [Signaleringsprotocol overgewicht in de jeugdgezondheidszorg]. Amsterdam, VUMC; 2004

49. van Buuren S: [Body-mass index cut-off values for underweight in Dutch children] Afkapwaarden van de 'body-mass index' (BMI) voor ondergewicht van Nederlandse kinderen. Ned Tijdschr Geneeskd 2004, I48:1967-1972.

50. Fredriks AM, van Buuren S, Fekkes M, Verloove-Vanhorick SP, Wit JM: Are age references for waist circumference, hip circumference and waist-hip ratio in Dutch children useful in clinical practice? Eur J Pediatr 2005, 164:216-222.

5I. Kemper HGC, Ooijendijk WTM, Stiggelbout M: Consensus over de Nederlandse Norm voor Gezond Bewegen. Tijdschr Soc Gezondheidsz 2000, 78:180-183.

52. Bulk-Bunschoten AMW, Renders CM, Leerdam FIM, Hirasing RA: Protocol for the prevention of childhood obesity in youth health care. [Overbruggingsplan voor kinderen met overgewicht; Methode voor individuele primaire en secundaire preventie in de jeugdgezondheidszorg]. Amsterdam, VUMC; 2005.

53. [http://www.voedingscentrum.nl].

54. Stunkard AJ, Sorensen T, Schulsinger F: Use of the Danish Adoption Register for the study of obesity and thinness. Res Publ Assoc Res Nerv Ment Dis 1983, 60: I I5-120.

55. Amorim LD, Bangdiwala SI, McMurray RG, Creighton D, Harrell J: Intraclass correlations among physiologic measures in children and adolescents. Nurs Res 2007, 56:355-360.

56. Twisk JWR: Applied Longitudinal Data Analysis for Epidemiology; A Practical Guide. Cambridge, Cambridge University Press; 2003.

57. Kain J, Uauy R, Albala, Vio F, Cerda R, Leyton B: School-based obesity prevention in Chilean primary school children: methodology and evaluation of a controlled study. Int J Obes Relat Metab Disord 2004, 28:483-493.

58. McKenzie TL, Nader PR, Strikmiller PK, Yang M, Stone El, Perry CL Taylor WC, Epping JN, Feldman HA, Luepker RV, Kelder SH: School physical education: effect of the Child and Adolescent Trial for Cardiovascular Health. Prev Med 1996, 25:423-43I.

59. Coleman KJ, Tiller CL, Sanchez J, Heath EM, Sy O, Milliken G, Dzewaltowski DA: Prevention of the Epidemic Increase in Child Risk of Overweight in Low-Income Schools: The EI Paso Coordinated Approach to Child Health. Arch Pediatr Adolesc Med 2005, 159:2 17-224.

60. Donnelly JE, Jacobsen DJ, Whatley JE, Hill JO, Swift LL, Cherrington A, Polk B, Tran ZV, Reed G: Nutrition and physical activity program to attenuate obesity and promote physical and metabolic fitness in elementary school children. Obes Res 1996, 4:229-243.

61. Simons-Morton BG, Parcel GS, Baranowski T, Forthofer R, O'Hara NM: Promoting physical activity and a healthful diet among children: results of a school-based intervention study. $\mathrm{Am}$ Public Health 1991, 81:986-991.

62. Jurg ME, Kremers SPJ, Candel MJJM, Van der Wal MF, Meij JSBD: A controlled trial of a school-based environmental intervention to improve physical activity in Dutch children: JUMP-in, kids in motion. Health Promot Int 2006, 21 :320-330.

63. Sallis JF, McKenzie TL, Alcaraz JE, Kolody B, Faucette N, Hovell MF: The effects of a 2-year physical education program (SPARK) on physical activity and fitness in elementary school students. Sports, Play and Active Recreation for Kids. Am J Public Health 1997, 87: 1328-1334

64. Caballero B, Clay T, Davis SM, Ethelbah B, Rock BH, Lohman T, Norman J, Story M, Stone EJ, Stephenson L, Stevens J: Pathways: a school-based, randomized controlled trial for the prevention of obesity in American Indian schoolchildren. Am J Clin Nutr 2003, 78: $1030-1038$

65. Manios Y, Moschandreas J, Hatzis C, Kafatos A: Health and nutrition education in primary schools of Crete: changes in chronic disease risk factors following a 6-year intervention programme. BrJ Nutr 2002, 88:3I5-324.

66. Danielzik S, Pust S, Muller MJ: School-based interventions to prevent overweight and obesity in prepubertal children: process and 4-years outcome evaluation of the Kiel Obesity Prevention Study (KOPS). Acta Paediatr Suppl 2007, 96:19-25.

67. Harrell JS, McMurray RG, Bangdiwala SI, Frauman AC, Gansky SA, Bradley CB: Effects of a school-based intervention to reduce cardiovascular disease risk factors in elementary-school children: the Cardiovascular Health in Children (CHIC) study. J Pediatr 1996, I 28:797-805.

68. Sahota P, Rudolf MC, Dixey R, Hill AJ, Barth JH, Cade J: Evaluation of implementation and effect of primary school based intervention to reduce risk factors for obesity. Bmj 200I, 323:1027-1029.

69. Goran MI: Measurement Issues Related to Studies of Childhood Obesity: Assessment of Body Composition, Body Fat Distribution, Physical Activity, and Food Intake. Pediatrics 1998, 101:505-518.

\section{Pre-publication history}

The pre-publication history for this paper can be accessed here:

\section{http://www.biomedcentral.com/1471-2458/8/257/pre} pub
Publish with Bio Med Central and every scientist can read your work free of charge

"BioMed Central will be the most significant development for disseminating the results of biomedical research in our lifetime. "

Sir Paul Nurse, Cancer Research UK

Your research papers will be:

- available free of charge to the entire biomedical community

- peer reviewed and published immediately upon acceptance

- cited in PubMed and archived on PubMed Central

- yours - you keep the copyright
BioMedcentral 